\title{
The Stylistic Amplification of Conceptual Metaphors in Translating Shakespeare into Arabic by Mohamed Enani
}

\author{
Lamis Ismail Omar \\ English Language and Literature Department \\ College of Arts and Applied Sciences \\ Dhofar University, Salalah, Sultanate of Oman
}

\begin{abstract}
Translating Shakespeare into Arabic is a century-old cultural project which is still a source of challenge for translators who adopt a source-text-oriented approach that attempts to simulate the original in content, form and impact. Shakespeare's texts are rife with metaphoric language which serves multiple functions on the cognitive, cultural, pragmatic as well as stylistic levels. This paper aims to analyse the translation of literary metaphors from a stylistic perspective in Mohamed Enani's version of Othello. The analysis is conducted in the framework of conceptual metaphor theory which provides a microscopic description of how metaphors are influenced by the translation process. The findings of the analysis unveil the translation strategy adopted by Enani to reflect the stylistic function of metaphors while preserving their cognitive content and reveals that translating metaphors is influenced by the cognitive and professional background of the translator. Amplification emerges as a successful translation strategy which is used to extend metaphors creatively thus adding cognitive value to the Source Text content and compensating for a possible loss in the style of the Target Text. This paper concludes that, contrary to the prevalent assumptions, a source-text-oriented approach can deliver an accurate yet stylistically-functional translation if the translator is creative enough and willing to exert an additional cognitive effort similar to that exerted by the original writer. Enani's translations of Shakespeare into Arabic are worth a life-long research project on the translation of style in literature.

Keywords: adaptation, amplification, domestication, conceptual metaphor theory, compensation, literary translation, stylistics, translating Shakespeare into Arabic, Othello
\end{abstract}

Cite as: Omar, L. I. (2020). The Stylistic Amplification of Conceptual Metaphors in Translating Shakespeare into Arabic by Mohamed Enani. Arab World English Journal for Translation \& Literary Studies 4 (4) 58 -71 . DOI: http://dx.doi.org/10.24093/awejtls/vol4no4.5 


\section{Introduction}

Shakespeare's works have been a rich subject for translation in all world languages over the past few centuries (Baker \& Saldanha, 2009). Translating the plays of Shakespeare into Arabic coincided with the advent of the Arabic Translation movement which was launched at the end of the nineteenth century when al-nahda started to prosper in Egypt giving birth to several intellectual and cultural activities in different fields of knowledge including medical studies, engineering, literature, language, art, etc. (Selim, 2019). This cultural revival movement which covered various aspects of life emerged when Muhammad Ali Pasha, the then Wali of Egypt, launched an initiative to import all forms of knowledge from the West, which prompted him to send students from diverse disciplines on scholarships abroad (Ead, 2019). Intellectuals like the Egyptian scholar Mohamed Abdou encouraged translation (Ennaji, 2005), and institutional bodies embarked on the intellectual project of 'transferring' works of science and art from Europe to Arab countries, a project that gave momentum to cultural and academic exchange programmes and inspired the translation of world literature into Arabic in the framework of what was known as harakat altarjama (Somekh, 1991).

Translating the works of Shakespeare into Arabic went through several phases but has never reached its culmination because there was always something lost in the translation. Translations which attempted to adopt a source-text-oriented approach fell short of reflecting the art of Shakespeare in one way or another until recently. This paper aims at investigating the translation of one of the most prominent and complex aspects of Shakespeare's works, namely metaphors by Mohamed Enani who has excelled in producing academic translations that are celebrated for their accuracy and success in preserving both the conceptual content and the stylistic properties of the original texts (Abdo \& Abu-Hammad, 2019). The study is significant in that it provides a minute analysis of what happens during the processing of conceptual metaphors by an experienced translator whose main objective is to yield a sincere representation of the ST's content and function. The paper tries to answer the following questions:

1. Is translating metaphor a purely conceptual process which can be conducted away from the experiential background of the translator?

2. Will adopting a source-text-oriented approach to the translation of metaphor limit the scope of a translation that seeks to simulate the style of the original?

3. What translation strategy can an experienced translator use in order to process metaphors in a way that fulfills the conceptual and stylistic component of the ST, and how effective can such translation strategy be?

The empirical study is conducted within the framework of the cognitive theory of metaphor, as clarified in the following steps:

1. Deconstructing ST metaphors and TT metaphors by their kernel conceptual metaphoric patterns to conduct the contrastive analysis between the two texts

2. Observing what happened during the translation of metaphor at the level of minute metaphoric components (basic metaphors and metaphoric concepts) rather the level of the image as a whole 
3. Highlighting the translation strategy used by Enani in processing the metaphoric content of the ST and the motive behind its use. The body of the text should be left justified in 12point Times New Roman font.

\section{Literature Review}

Shakespeare was "one of the first western writers to be translated and introduced to the Arab audience and readership" (Fawzi \& Yasir, 2017, p. 343) and his plays were among the top works of world literature to be represented in Arabic and acted "on the Arab stage" (al-Shetawi, 1989, p. 119). The Arabic translations of Shakespeare's plays went through gradual development between adaptation and academic translation. The first Arabic translations of Shakespeare were conducted to be acted on the stage (Twaij, 1973) as adaptations of the Source Texts (STs) that were changed to embrace "the conventions of native drama and ... the taste of the audience" (alShetawi, 1989, p. 115). These adaptations dealt with the original texts quite flexibly thus introducing several changes to the ST's components such as the setting, characterization, plot, etc. An example of this is Najib al-Haddad's adaptation of Shakespeare's Romeo and Juliet (1891) as "Martyrs of Love (Shuhadā' al-Gharām)" (Litvin, 2011, p. 63)

When the term 'adaptation' is used in Translation Studies (TS) to refer to a process taking place on the level of the Source Text as a whole, it involves an extensive sequence of changes in ST properties including the deletion of certain components, introducing new components to the content of the ST, and shifting some components. But if the changes introduced to the ST are "applied selectively, for example to names of people and places only, the translation as a whole may not strike a reader or critic with access to the original as an adaptation" (Classe, 2000, p. 2). The adaptations of Shakespeare's works into Arabic influenced the content of the STs considerably by deleting substantial parts of them and made changes in the plot, linguistic content as well as style of the original texts. Some adaptations went as far as toning down the ST tenor using the spoken Egyptian dialect instead of standard Arabic. One example of these adaptations is the Arabic translation of Shakespeare's Hamlet by Tanyus ${ }^{c} A b d u h$ (1901). This translation which is "the earliest surviving Arabic Hamlet" (Litvin, 2011, p. 10) changed a great deal in the content and ending of the play and was therefore criticized for being far removed from the ST (al-Shetawi, 1989) and distorting its content. Yet, there is no denying that that the adaptations of Shakespeare that aimed to appeal to "the local taste and colour of the area" (al-Shetawi, 1989, p. 124) made the Bard quite popular in the Arab world.

The adaptations of Shakespeare into Arabic were performed by local theatre groups that used the Egyptian dialect in presenting the content of the plays. But due to cultural exchange activities, the beginning of the twentieth century witnessed the arrival of professional theatre groups from European countries like Italy, France and England to give performances in Egypt. One of these groups was the English Shakespeare Company which visited Egypt to perform some Shakespearean plays in two seasons in 1927 and 1928 (al-Shetawi, 1989). The performances of Shakespeare's plays by professional groups exposed the audience to the actual content of the plays, which made them critical of the adapted translations for the massive changes that influenced the main components of the STs. In response to this criticism, prominent literary figures were prompted to retranslate Shakespeare's plays in a way which preserved the main components of the 
STs and introduced slight changes to certain linguistic and cultural properties. The changes were limited to rephrasing some sentences and expressions or replacing them with more natural ones from the perspective of the target language.

This strategy in approaching the ST is called 'Arabization' when translating from English into Arabic and 'domestication' in other language combinations. Unlike adaptation, domestication takes place on the level of individual textual components influencing specific lexical units (by deletion or naturalization) such as culturally-embedded items (with references to food, religion, or social practices), names, stylistic components, etc. The main purpose of domestication is to naturalize the content of the TT and make it readable in the target language (Wright, 2016). Arabization (the Arabic form of domestication) or $t a^{c} r \bar{i} b$ refers to a translation technique which aims at representing a ST in Arabic by adapting its lexical and cultural components to the Arabic language without leaving an impact on its structure and thematic content (al-Shetawi, 1989-Khalil Mutran adopted Arabization in translating Shakespeare's Othello, ${ }^{C}$ Utail, published in 1912 (Hanna, 2009). Mutran explained that he used Arabization to make these plays linguistically and conceptually accessible to the readers and/or audience (Ghazoul, 1998). In his introduction to the translation of Othello, Mutran remarked that Arabization was mainly applied to the metaphorical content of the play to make it readable by the target audience (Shakespeare, 1993).

Mutran's contribution was a turning point "in the history of Arabic representations of the Bard and his work" (Hanna, 2007, p.28) because it was meant to give a very close translation of the plays of Shakespeare into Arabic focusing on the content and structural components of the ST while trying to domesticate certain lexical units to make them natural to the readers. Accordingly, he made selective shifts on the level of sentences and smaller lexical items that were replaced with natural equivalents vis-à-vis the target language and culture. The main distinction between adaptation and domestication in translating Shakespeare's plays is that the first was liberal in dealing with the ST as a whole, while the second preserved the basic components of the ST and introduced changes to some lexical components to naturalize its linguistic content.

After the second half of the twentieth century, the plays of William Shakespeare started to be retranslated into Arabic by the initiative of certain cultural and academic bodies like the Arab League's Cultural Committee which initiated the 1950s intellectual project of translating the works of Shakespeare into Arabic (Enani, 2006). This scholarly project was entrusted to outstanding "literary figures and translators in the Arab world" (Tounsi, 1989, p. 51) like Jabra Ibrahim Jabra who was the first to produce academic translations of Shakespeare's plays. The translations that emerged at that time did not adopt a liberal approach to the ST and attempted to represent it carefully without modifications in its content, plot, characters, or linguistic properties. According to early academic research on the Arabic translations of Shakespeare, these translations were ranked as highly intellectual accomplishments considering their celebrated 'accuracy' and authentic representation of the original texts (Twaij, 1973; Zaki, 1978).

Following the Arab League's initiative accuracy was the main criteria for representing the bard, which gave rise to critical studies that sought to evaluate the translated works "to improve the (...) Arabic versions of Shakespeare" (Alsaai, 1997, p. 35). These critical studies focused on 
the approaches and strategies used by different translators to reflect the content and language of Shakespeare and highlighted "the major problems which confront translators" (Alsaai, 1997, p. 37). The first category of critical studies celebrated the adaptations of Shakespeare's plays into Arabic despite their liberal approach to the topic, structure and characterization of the STs. Critics from this group did not discuss any of the aspects relating to the Bard's language. These studies commended the Arabic "recreations of Shakespeare" (Kanaan, 1998, p. 219) for the role they played in introducing theatre to the Arab audience; the adaptations succeeded in reflecting the concerns of the target readers by borrowing the thematic content of Shakespeare's plays then adapting them to shine a light on local issues. In other words, the adaptations of Shakespeare into Arabic attempted to put the STs within the socio-cultural and political framework of the recipients (Litvin, 2011; Al-Shetawi, 2013), by focusing on "macro-level cultural categories rather than micro-level linguistic structures" (Hanna, 2006, p. 13). Studies that defended the adaptations of Shakespeare's plays pointed out that the language of Shakespeare is not translatable in a one-toone correspondence because of certain linguistic and cultural limitations:

the purist's ideal of a good and faithful translation of Shakespeare's text into a foreign language, not to mention the translation of Shakespearean themes into foreign cultures, is in reality an impossibility. English metrical niceties, word-plays, imagery, emphases, insinuations, skillful repartee, and the atmospheric use of colour in verse and prose may all evaporate in a straightforward Arab representation of Shakespeare. (Kanaan, 1998, p. 219)

Another group of critical studies discussed the translations of Shakespeare into Arabic from the perspective of the STs' linguistic and conceptual components, rather than the strategies used to adapt them to Arabic language and culture. Such studies postulated that Shakespeare's works received critical acclaim in the English culture and worldwide thanks to the language and style adopted by the Bard to present his characters and ideas on the page before they were even reflected on the stage. This yielded an authoritative status to the ST and highlighted the importance of observing accuracy as the main criteria in translating Shakespeare's works successfully. SToriented studies carried out a deep analysis of the challenges faced by translators while processing concepts and lexical items that have cultural connotations in the works of Shakespeare. Such concepts comprise lexical items which are religiously-embedded, objects which belong to the natural environment like birds, plants, "precious stones and gems" (Zaki, 1978, p. 74) as well as lexical items with indirect connotations like jokes, idioms "figures of speech" (Tounsi, 1989, p. 95), "metaphors, puns, and wordplay" (Al-Thebyan et al, 2001, p. 65).

Examples of research that reviewed the translation of Shakespeare's works into Arabic from the perspective of the ST include the academic research conducted by Zaki (1978), Alsaai (1997) and Omar (2012). The first two studies dealt with the challenges facing the translators during the translation process and proposed some solutions to improve the excellence of the translated works. Zaki (1978) stated that "only a few of Shakespeare's plays and poetical works that have been translated into Arabic are regarded as accurate renditions combining both sound scholarship and literary merit" (p. 300). Nonetheless, these translations have certain shortcomings as a result of several factors that disrupted the translation process such as the lack of knowledge about the characteristics of Renaissance literature and English literature and "the translators' 
unfamiliarity with basic tools of research needed both in translation generally and Shakespearean translation in particular" (Zaki, 1978, p. 76). Accordingly, the task of the translator is not confined to reflecting the ST in a well-integrated TT that observes diverse levels of equivalence vis-à-vis the ST. Shakespeare's translators need to be involved in an arduous task which requires investing in all the available tools of research like relevant glossaries and authoritative editions that are annotated by various scholars in the field (Zaki,1978).

Omar (2012) reviewed the development of the translation of Shakespeare from English into Arabic and conducted an empirical research which focused on the translation of conceptual metaphors in Shakespeare's language in TTs that received critical acclaim for their contribution to translating the heritage of Shakespeare into Arabic. The researcher concluded that the issues encountered by different translators in dealing with the metaphoric language of the Bard are mainly cognitive, and the translation product tends to be influenced by two sets of factors: the first has to do with the universality/diversity of metaphors on the cultural, contextual, and pragmatic levels; and the second has to do with the background knowledge of the translators as well as their theoretical framework and experiential background.

Overall, there are two types of global translation strategies that distinguished the translations of Shakespeare. The first adopted a TT-oriented approach that focused on the readability of the TT vis-à-vis the target language and culture, whereas the second embraced a SToriented approach which observed the principles of accuracy and loyalty to the ST (Almanna, 2016). Whether the translator adopts a TT-oriented approach or a ST-oriented approach to translating Shakespeare's plays into Arabic or any other text in any language combination depends on the skopos of the translation process. The skopos theory, developed by Reiss and Vermeer in the eighties of last century, views any translation process as "a purposeful activity" (Palumbo, 2009, p. 107) in which a translator has a certain goal that influences their choice of local translation strategies (Almanna, 2016) during the process of translation. The question here is whether a SToriented approach can yield a creative translation that preserves the conceptual content of the ST without leaving an impact on its stylistic functions. To answer this question, the next section will examine an excerpt from a translation which adopted a ST-oriented approach to Shakespeare's works and at the same time received critical acclaim as an academic, yet creative piece of work. The excerpt is taken from Mohamed Enani's translation of Othello.

Among the most accomplished translations of Shakespeare into Arabic are those produced by Mohamed Enani who showed unparalleled dedication and creativity in translating Shakespeare's works. Enani is a TS professor and critic, Shakespeare scholar, academic writer, novelist, playwright, poet, as well as professional translator who has so far authored and translated over " 130 books in both Arabic and English, varying from translations to critical and creative works" (Abdo, \& Abu-Hammad, 2019, p. 021) including twenty-four Shakespeare plays and the Sonnets (Enani, 2016). Since the Arab League's decision to translate the complete works of Shakespeare into Arabic, Enani has dedicated himself to this significant project guided by the academic input of critics on these works since they emerged (Enani, 2006). Enani wrote detailed introductions to his translations, explaining how the translations benefited from several editions of the STs and highlighting the translation strategies used in approaching the STs. Additionally, Enani 
expressed his interest in translating metaphors in his account on idiomatic expressions (Enani, 2004) which focused mainly on reflecting the pragmatic and stylistic function of metaphors. Enani's translations have been commended for their loyalty, accuracy and creativity in representing Shakespeare works. According to Alsaai (1997), Enani gave "one of the finest examples so far of how to translate Shakespeare into Arabic" (p. 300) as he was successful in reflecting the ST properties in an accomplished and refined manner that yielded an authentic embodiment of Shakespeare's language and style.

The case study in this paper will examine one aspect of Enani's approach to translating metaphors in Othello from the perspective of Conceptual Metaphor Theory (CMT), highlighting the importance of this theory for conducting a conceptual comparative analysis between STs and TTs and shining a light on Enani's strategy in translating one of the most challenging literary texts in English literature.

\section{Methods}

This section will provide a brief theoretical framework of CMT which will be applied to the analysis of translating metaphors in an excerpt from Othello. The conceptual theory of metaphor does not view metaphor as a linguistic or ornamental tool with uses that are exclusive to the disciplines of literature and rhetoric. Rather, metaphor is seen as a ubiquitous conceptual process that is embedded in our reasoning and pervasive in all disciplines. This theory is also known as 'the cognitive theory of language and thought' since it highlights the conceptual uses of metaphor in our thinking as "a way of experiencing the facts" and "a way of thinking and of living" (Hawkes, 1972, p. 39). CMT was first introduced by Lakoff and Johnson in their book Metaphors We Live By (1980) and then it was developed by Lakoff and Turner (1989); Lakoff and Johnson (1999); and others. According to CMT, meaning is a conceptual, physically-embedded experiential phenomenon which results from the interaction between our conceptual system, the mind, and our physical system, the body.

The cognitive school distinguished between metaphoric expressions and conceptual metaphors. Conceptual metaphors are patterns that relate a certain domain/concept (the target domain) to a specific experience (source domain/concept) under the basic structure (TARGET DOMAIN IS SOURCE DOMAIN). On the other hand, metaphoric expressions are linguistic structures which embody basic conceptual metaphors. Different conceptual metaphors show variation at least in one of the following components: target domain, source domain, and the relationship that holds between the two. A conceptual metaphor can generate a wide spectrum of diverse metaphoric expressions. We can take the concept of LOVE as an example of a target domain in the following excerpt, "love is a smoke made with the fume of sighs. Being purged, a fire sparkling in lovers' eyes. Being vexed, a sea nourished with lovers' tears (...) A madness most discreet" (Shakespeare, 2016, p. 1006-1007). These expressions which delineate the concept of love as 'smoke', 'fire', 'sea', 'mental disorder", etc. are representations of the conceptual metaphor that sees "love" as a "natural/physical force".

In the following example, the basic conceptual metaphors will be extracted from both the ST and TT and then compared to highlight any mutation that may have influenced the ST content. 
This will pave the way for observing the translation strategy/strategies adopted in producing the TT. The ST is Shakespeare's Othello and the TT is Enani's Arabic translation of the ST. The selected example is taken from a speech by Brabantio. Brabantio's daughter, Desdemona elopes with Othello, gets married to him and refuses to return to her father. The ST passage appears in the form of wisdom which is uttered by Desdemona's father, Brabantio, when the Duke asks him to defeat his sorrow with a triumphant smile. The translated text shows that Enani endeavoured to provide an accurate translation of the ST content while attempting to reflect the rhythmical component which is one of the stylistic characteristics of Shakespeare's dramatic language. The tables below will provide the analysis of ST conceptual metaphors and TT conceptual metaphors.

Table 1. The ST passage, the TT passage and a back translation of the TT

\begin{tabular}{|c|c|c|}
\hline ST & TT & Back Translation \\
\hline $\begin{array}{l}\text { "So let the Turk of Cyprus us beguile; } \\
\text { We lose it not so long as we can smile } \\
\text { He bears the sentence well, that } \\
\text { nothing bears } \\
\text { But the free comfort which from } \\
\text { thence he hears; } \\
\text { But he bears both the sentence and the } \\
\text { sorrow } \\
\text { That, to pay grief, must of poor } \\
\text { patience borrow; } \\
\text { These sentences, to sugar or to gall, } \\
\text { Being strong on both sides, are } \\
\text { equivocal; } \\
\text { But words are words I never did hear } \\
\text { That the bruised heart was pierced } \\
\text { through the ear" } \\
\text { (Shakespeare, } 2005 b \text {, Othello, } \\
\text { 1.3.210-219) }\end{array}$ & 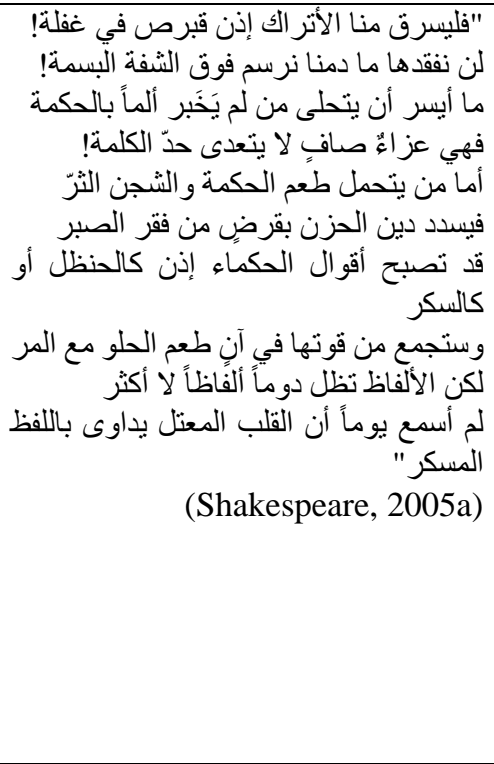 & $\begin{array}{l}\text { Let the Turk, then, steal Cyprus } \\
\text { from us while we are busy } \\
\text { We do not lose it so long as we can } \\
\text { draw a smile on our lips } \\
\text { It is so easy for someone who did } \\
\text { not suffer to be wise; } \\
\text { It is a pure comfort that does not go } \\
\text { beyond the limits of words; } \\
\text { But he who bears the taste of } \\
\text { wisdom and hard sorrow } \\
\text { Borrows from poor patience to pay } \\
\text { the debt of grief; } \\
\text { The words of wise people might act } \\
\text { like sugar or colocynth; } \\
\text { Powerful on both sides, they bring } \\
\text { the sweet with the bitter; } \\
\text { But utterances remain utterances; } \\
\text { I did never hear that a sick heart is } \\
\text { cured with intoxicating words }\end{array}$ \\
\hline
\end{tabular}

The following table provides a conceptual analysis of the ST metaphors.

Table 2. ST basic conceptual metaphors

\begin{tabular}{|l|l|}
\hline ST & Conceptual Metaphors \\
"So let the Turk of Cyprus us beguile; & OCCUPYING IS STEALING A PRECIOUS OBJECT \\
He bears the sentence well, that nothing bears & THE OBJECT OF OCCUPATION IS A PRECIOUS \\
But the free comfort which from thence he hears; & OBJECT \\
But he bears both the sentence and the sorrow & A SENTENCE IS A HEAVY OBJECT \\
That, to pay grief, must of poor patience borrow; & FEELING SORROW IS CARRYING A HEAVY \\
These sentences, to sugar or to gall, & OBJECT \\
Being strong on both sides, are equivocal; & SORROW IS A HEAVY OBJECT \\
But words are words I never did hear & GRIEF IS A CREDITOR \\
That the bruised heart was pierced through the ear" & PATIENCE IS A LENDER \\
(Othello, $1.3 .210-219)$ & PATIENCE IS A POOR PERSON \\
& WORDS ARE FOOD (HAVE A TASTE) \\
& SADNESS IS A BRUISE IN THE HEART \\
& A SAD HEART IS THE OBJECT OF BRUISE \\
\end{tabular}

Arab World English Journal for Translation \& Literary Studies 
AWEJ for Translation \& Literary Studies Volume, 4 Number 4. October 2020

The Stylistic Amplification of Conceptual Metaphors in Translating Shakespeare

Omar

The following table provides the back translation of the TT and the analysis of the TT conceptual metaphors.

Table 3. TT basic conceptual metaphors

\begin{tabular}{|l|l|}
\hline Back Translation of the TT & Conceptual Metaphors \\
\hline Then let the Turk steal Cyprus of us while we are busy & OCCUPYING IS STEALING A PRECIOUS OBJECT \\
We will not lose it if we can draw a smile on the lips & THE OBJECT OF OCCUPATION IS A PRECIOUS \\
It is easy for someone who did not suffer to be wise; & OBJECT \\
This is an absolute comfort that does not exceed the limit & A SMILE IS A PIECE OF ART \\
of words; & SMILING IS PRODUCING A PIECE OF ART \\
But the person who accepts the taste of wisdom and & WORDS HAVE PHYSICAL DIMENSIONS \\
painful sorrow & (BORDERS) \\
Borrows from poor patience to pay the debt of grief; & WISDOM IS FOOD (HAS A TASTE) \\
The words of wise people might act like sugar or & WISDOM IS A HEAVY OBJECT \\
colocynth; & SADNESS IS A HEAVY OBJECT \\
their strength makes them bring the sweet with the bitter; & GRIEF IS A CREDITOR \\
But utterances remain utterances; & PATIENCE IS A LENDER \\
I did never hear that a sick heart is cured with & WORDS ARE FOOD (HAVE A TASTE) \\
intoxicating words & WORDS HAVE A PHYSICAL FORCE/POWERFUL \\
& A SAD HEART IS THE OBJECT OF SICKNESS \\
& SADNESS IS A DISEASE \\
& WORDS ARE MEDICINE \\
& WORDS ARE ALCOHOL \\
& HEALING SADNESS IS HEARING WORDS \\
\hline
\end{tabular}

The following table provides the conceptual metaphors of the ST and the conceptual metaphors of the TT.

Table 4. ST conceptual metaphors versus TT conceptual metaphors

\begin{tabular}{|l|l|}
\hline ST Conceptual Metaphors & TT Conceptual Metaphors \\
\hline OCCUPYING IS STEALING A PRECIOUS OBJECT & OCCUPYING IS STEALING A PRECIOUS OBJECT \\
THE OBJECT OF OCCUPATION IS A PRECIOUS & THE OBJECT OF OCCUPATION IS A PRECIOUS \\
OBJECT & OBJECT \\
PATIENCE IS BEARING A HEAVY OBJECT & A SMILE IS A PIECE OF ART \\
A VERDICT IS A HEAVY OBJECT & SMILING IS PRODUCING A PIECE OF ART \\
FEELING SORROW IS CARRYING A HEAVY & WORDS HAVE PHYSICAL DIMENSIONS \\
OBJECT & (BORDERS) \\
SADNESS IS A HEAVY OBJECT & WISDOM IS FOOD \\
GRIEF IS A CREDITOR & WISDOM IS A HEAVY OBJECT \\
PATIENCE IS A LENDER & FEELING SORROW IS CARRYING A HEAVY \\
PATIENCE IS A POOR PERSON & OBJECT \\
WORDS ARE FOOD & SORROW IS A HEAVY OBJECT \\
SADNESS IS A BRUISE IN THE HEART & GRIEF IS A CREDITOR \\
A SAD HEART IS THE OBJECT OF BRUISE & PATIENCE IS A LENDER \\
WORDS HAVE A PHYSICAL FORCE & WORDS HAVE A PHYSICAL FORCE \\
& WORDS ARE FOOD \\
& A SAD HEART IS THE OBJECT OF SICKNESS \\
& SADNESS IS A DISEASE \\
WORDS ARE MEDICINE \\
WORDS ARE ALCOHOL \\
\hline
\end{tabular}

Arab World English Journal for Translation \& Literary Studies

ISSN: 2550-1542 | www.awej-tls.org 


\section{Findings}

The results of the analysis show that there are slight changes in the content of the ST; but these changes did not influence the conceptual content of the image as a whole. They rather influenced certain components. To clarify, the translator's concern with the poetic style of the passage left an impact on certain components of the ST's metaphoric patterns, with the result of causing mild loss in certain components and shifts in other components. Enani's aim was to preserve the stylistic feature of the ST without damaging its metaphoric content. For this end, the translator preserved the basic conceptual metaphors that breathe life into the conceptual content of the main images like the extended metaphor of 'EMOTION AS A PERSON' (an ontological metaphor) and the metaphor of 'OCCUPYING A COUNTRY AS STEALING A PRECIOUS OBJECT' (structural metaphor).

The resulting change in the metaphors of the ST took three forms: marginal loss in ST conceptual metaphors, slight shifts in ST conceptual metaphors and creating new conceptual metaphors in the TT. For instance, there are some shifts in some components of a limited number of conceptual metaphors as in changing the SD concept of the conceptual metaphor 'A SAD HEART IS THE OBJECT OF BRUISE' to 'A SAD HEART IS THE OBJECT OF DISEASE. Also, the conceptual metaphor "WORDS HAVE A PHYSICAL FORCE" was changed into "WORDS ARE ALCOHOL/HAVE AN INTOXICATING EFFECT".

The conceptual metaphor which depicts 'SORROW AS A PHYSICAL FORCE' (an image schema) was changed to the structural metaphor which sees 'SORROW AS A DISEASE'. Also, in an attempt to come up with words that respond to the stylistic component of the wisdom, the TT introduced novel metaphoric structures to the metaphoric component of the ST, as in the case of the following metaphors: 'A SMILE IS A PIECE OF ART', 'WORDS ARE MEDICINE', 'HEALING SADNESS IS HEARING WORDS'. It is noticed that the novel metaphoric patterns which were incorporated with the metaphoric fabric of the ST are in harmony with the conceptual domains of the individual metaphors and the image as a whole. The following table provides an analysis of the changes in the ST data due to the translator's keenness to reflect the style of the ST:

Table 5: Mutation in the ST metaphoric content

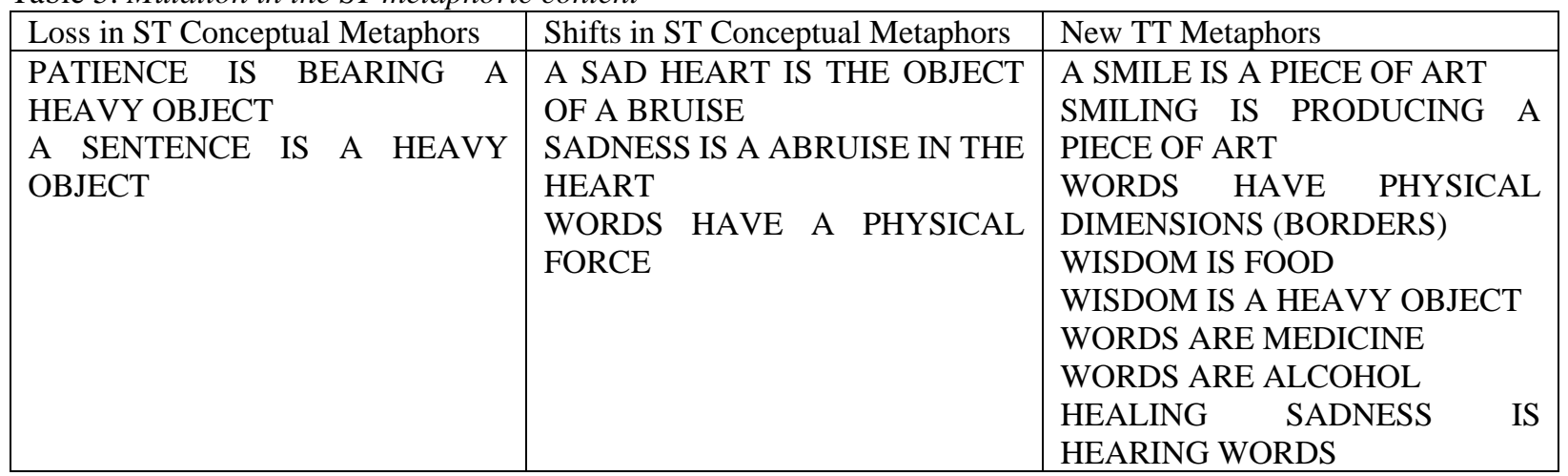

Arab World English Journal for Translation \& Literary Studies 


\section{Discussion: Compensation by Metaphor Amplification}

It is clear from the previous analysis of conceptual metaphors that the ST metaphors have a simple, cultural-free content and involve no cognitive or cultural complexities or issues, which means that they can be reflected in the TL without any mutation in their content, and it is also clear that Enani was very careful not to influence the conceptual content of ST metaphors. Nonetheless, the ST metaphoric content went through slight changes that appeared as a result of using the strategy of amplification for stylistic reasons. Almanna (2016) defines amplification as a local translation strategy which involves extending the ST component by "by the addition of some elements to it" (2016). This analysis reveals that, irrespective of Enani's endeavour to provide an accurate translation of Shakespeare's metaphoric language, the translation was influenced by empirical factors on the level of the ST and the translator's approach to translating it into the TL. These factors include the stylistic properties of the ST and the translator's scholarly and professional framework which has eventually shaped his skopos.

In his academic research and critical studies, Enani $(2016 ; 2020)$ has always highlighted the importance of reflecting style in translating works of literature. the translator's use of the strategy of amplification came as a successful procedure to compensate for an inevitable loss in the stylistic component of the ST which may have emerged due to a very strict representation of every single conceptual metaphor. What the translator did was to preserve the main conceptual metaphoric patterns and extend some of them to add a rhythmical flavour to the TT. Some ST metaphors were amplified and used as a means for fulfilling a certain stylistic aspect, instead of being an end which may cripple the endeavours of a translator to create a TT response that simulates the spirit of the ST.

There is a general assumption that adopting a ST-oriented approach to translating a certain text may succeed in reproducing the conceptual content of the ST at the expense of submerged textual features like the ST's stylistic component. The discussion has revealed that the translator succeeded in striking a balance between these two components by building on the ST conceptual metaphors to recreate the stylistic effect. This type of translation is neither a loose adaptation inspired by a TT-oriented approach, nor a fettered translation that follows a strict ST-oriented approach. It involves exerting additional efforts by the translator to compensate for a possible loss in the style of the ST. The translator has endeavoured to reflect translation as an act of gaining rather than losing, and a simulation of the original text both in body and spirit, while not losing track of the principle of accuracy which is the measure for academic translations.

\section{Conclusion}

Translators of Shakespeare, and literature in general, are faced with myriad challenges that include, but are not limited to, processing the metaphoric language of the ST and reflecting its stylistic features. Translating literary metaphors may not necessarily be a source of cognitive challenge for the translator. Rather, it is a conceptual process which is affected by experiential factors like the stylistic aspects of the ST and the skopos of the translator (Younis, 2017). Conceptual metaphor analysis functions as a microscope for unveiling minute details about what happens during the process of translation because in a translation which may seem fully accurate at a first glance it is noticed that the mutation that influenced the ST content during the process of 
translation did not disrupt the image, as a whole. Rather, it left an impact on smaller elements of the image like the SD or TD of the ST's conceptual metaphors.

Accordingly, it is more objective to view the translation of metaphor as a conceptual process rather than a cognitive challenge. This process is under the influence of the translator's approach to their ST in general whether they are concerned with the stylistic aspect of the ST or any other aspects. Regardless of the translator's commitment to a precise translation of the ST metaphors, the product of the translation process will continue to be subject to other factors such as the translator's cognitive orientation as well as empirical factors that are grounded in the ST properties. Finally, the analysis above reveals that the strategy of amplification can be effective in maintaining the metaphoric content of the ST without disrupting its stylistic properties. it is worth mentioning that Enani's extension of the ST conceptual metaphors required additional cognitive effort on his part but certainly the extended components were relevant and added cognitive as well as stylistic value to the TT without distorting the ST content or style. The new source domains, target domains or basic conceptual metaphors that were introduced to the metaphoric content were well contextualized and flow naturally and smoothly in the Arabic language TT.

\section{About the Author:}

Dr Lamis Ismail Omar is Assistant Professor of Translation and EFL at Dhofar University, Oman. She holds a doctorate in Translation Studies from Durham University, the UK. She taught translation, conference interpreting, EFL and literary criticism at Damascus University, and she also has long professional experience in English/Arabic translation and conference interpreting. Her research interests include translation and conference interpreting, the conceptual theory of metaphor, Shakespeare's metaphors as well as teaching English as a Foreign Language.

\section{https://orcid.org/0000-0003-0246-5613}

\section{References}

Abdo, I. B., \& Abu-Hammad, I. (2019). Stylistic issues in translating metaphors of Shakespeare's Merchant of Venice. Merit Research Journal of Education and Review, 7(3), 019-025.

Almanna, A. (2016). The Routledge course in translation annotation: Arabic-English-Arabic. London: Routledge Taylor \& Francis Group.

Alsaai, H. J. (1997). A critical assessment of the translations of Shakespeare into Arabic (Unpublished doctoral dissertation). The University of London, London.

Al-Shetawi, M. F. (1989). Shakespeare in Arabic: An overview. New Comparison: A Journal of Comparative and General Literary Studies, 8, 114-126.

Al-Shetawi, M. F. (2013). Arabic adaptations of Shakespeare and postcolonial theory. Critical Survey, Special Issue: Creating Shakespeare, 25(3), 4-28.

Al-Thebyan, Q. A., Al-Shalabi, N. T., Salameh, F. A., Al-Omari K. M. (2011). A critique of Jabra's Arabic translation of Shakespeare's the Tempest. Canadian Social Science, 7(6). 64-74. DOI: 10.3968/j.css.1923669720110706.022

Baker, M., \& Saldanha, G. (eds.). (2009). Routledge encyclopaedia of translation studies (2 ed.). London and New York: Routledge. 
AWEJ for Translation \& Literary Studies Volume, 4 Number 4. October 2020

The Stylistic Amplification of Conceptual Metaphors in Translating Shakespeare

Omar

Classe, O. (Ed.). (2000). Encyclopaedia of literary translation into English Vol. 1. London; Chicago: Fitzroy Dearborn Publishers.

Ead, H. A. (2019). Globalization in higher education in Egypt in a historical context. Research in Globalization, 1, 1-5. https://doi.org/10.1016/j.resglo.2019.100003

Enani, M. (2004). Fann al-tarjama [the Art of Translation] ( $7^{\text {th }}$ ed.). Cairo: The Egyptian International Publishing Company Longman.

Enani, M. (2006, April 13). On translating Shakespeare into Arabic. Al-Ahram Weekly Online. Retrieved from https://www.masress.com/en/ahramweekly/13707

Enani, M. (2016). On translating Shakespeare's Sonnets into Arabic. Critical Survey, 28(3), 119132. DOI: https://doi.org/10.3167/cs.2016.280308

Enani, M. (2020). On translating style into Arabic and into English: A stylistic approach to translation. Cairo: The Anglo-Egyptian Bookshop.

Ennaji, M. (2005). Multilingualism, cultural identity, and education in Morocco. New York: Springer.

Fawzi, M. \& Yasir, A. (2017). Shakespeare's Arab journey: A few considerations on the reception of Shakespeare in the Arab world. In M. Burada, O. Tatu and R. Sinu (eds.) $13^{\text {th }}$ Conference on British and American Studies: Language Identity and Diversity in a Globalized World (pp. 339-356). Cambridge Scholars Publishing.

Ghazoul, F. J. (1998). The Arabization of Othello. Comparative Literature, 50(1), 1-31.

Hanna, S. F. (2006). Towards a sociology of drama translation: A Bourdieusian perspective on translations of Shakespeare's great tragedies in Egypt (Unpublished doctoral dissertation). University of Manchester, Manchester.

Hanna, S. F. (2007). Decommercialising Shakespeare: Mutran's translation of "Othello". Critical Survey, 19(3), 27-54.

Hanna, S. F. (2009). Othello in the Egyptian vernacular: Negotiating the 'doxic' in drama translation and identity formation. The Translator, Special Issue Nation and Translation in the Middle East, 15(1), 157-178. https://doi.org/10.1080/13556509.2009.10799275

Hawkes, T. (1972). Metaphor. Methuen: Terence Hawkes.

Kanaan, F. (1998). Shakespeare on the Arab Page and Stage (Unpublished doctoral dissertation). The University of Manchester, Manchester.

Lakoff, G., \& Johnson, M. (1980). Metaphors we live by. Chicago: University of Chicago Press.

Lakoff, G., \& Johnson, M. (1999). Philosophy in the flesh. New York: Basic Books.

Lakoff, G., \& Turner, M. (1989). More than cool reason: A field guide to poetic metaphors. Chicago: University of Chicago University.

Litvin, M. (2011). Hamlet's Arab journey: Shakespeare's prince and Nasser's ghost. Princeton: Princeton University Press.

Omar, L. (2012). A cognitive approach to the translation of creative metaphor in Othello \& Macbeth from English into Arabic (Unpublished doctoral dissertation). Durham University, Durham.

Palumbo, G. (2009). Key terms in translation studies. London: Continuum International Publishing Group.

Selim, S. (2019). Popular fiction, translation and the Nahda in Egypt. Switzerland: Palgrave Macmillan.

Shakespeare, W. (1993). ${ }^{C}$ Utail [Othello] ( $7^{\text {th }}$ ed.). (K. Mutran, Trans.). Cairo: Dar al-Macārif.

Arab World English Journal for Translation \& Literary Studies 
Shakespeare, W. (2005a). The tragedy of Othello, the Moor of Venice (M. Enani, Trans.). Cairo: The General Egyptian Book Organization.

Shakespeare, W. (2005b). Romeo and Juliet. D. Bevington (Ed.), The necessary Shakespeare $\left(2^{\text {nd }}\right.$ ed., pp. 187-191). New York: Pearson/Longman.

Shakespeare, W. (2016). The new Oxford Shakespeare: The complete works, ( $2^{\text {nd }}$ ed.), G. Taylor, J. Jowett, T. Bourus and G. Egan (Eds.). Oxford: Oxford University Press.

Somekh, S. (1991). Genre and language in modern Arabic literature. Studies in Arabic language and literature, 1 , xii-141. Wiesbaden.

Tounsi, M. M. A. (1989). Shakespeare in Arabic: a study of the translation, reception, and influence of Shakespeare's drama in the Arab world (Published dissertation). University of Northern Colorado, USA.

Twaij, M. B. (1973). Shakespeare in the Arab world, (Unpublished doctoral dissertation). Illinois: North Western University.

Wright, C. (2016). Literary translation. London: Routledge Taylor \& Francis Group.

Younis, I. (2017). Shakespeare images between loss and compensation in Arabic translation: A skopos perspective. Latvia: Noor Publishing.

Zaki, A. A. (1978). Shakespeare in Arabic (Unpublished doctoral dissertation). Indiana University, Indiana. 